Advanced Computing: An International Journal ( ACIJ ), Vol.2, No.6, November 2011

\title{
COMPUTATION OF TRANSFORMER LOSSES UNDER THE EFFECTS OF NON- SINUSOIDAL CURRENTS
}

\author{
Amit Gupta ${ }^{1}$, Ranjana Singh ${ }^{2}$ \\ ${ }^{1}$ PG Scholar, HVPS, Department of Electrical Engineering, Jabalpur Engineering \\ College \\ amit.hvps@gmail.com \\ ${ }^{2}$ Associate Professor, Department of Electrical Engineering, Jabalpur Engineering \\ College \\ ranjana_n_singh@.yahoo.co.in
}

\begin{abstract}
Transformers are normally designed and built for use at rated frequency and perfect sinusoidal load current. A non-linear load on a transformer leads to harmonic power losses which cause increased operational costs and additional heating in power system components. It leads to higher losses, early fatigue of insulation, premature failure and reduction of the useful life of the transformer. To prevent these problems, the rated capacity of transformer which supplies harmonic loads must be reduced. In this work a typical 100 KVA three phase distribution transformer with real practical parameters is taken under non-linear loads generated due to domestic loads. The equivalent losses and capacity of the distribution transformer is evaluated using the conventional method \& also by using soft computing technique using MATLAB simulation based on valid model of transformer under harmonic conditions. And finally a relation associated with transformer losses and life assessments are reviewed \& analyzed and then a comparison is being carried out on the results obtained by both the methods.
\end{abstract}

KEYWORDS-Transformer losses; Harmonic loads; Derating;

\section{INTRODUCTION}

In recent years, there has been an increased concern about the effects of nonlinear loads on the electric power system. Nonlinear loads are any loads which draw current which is not sinusoidal and include such equipment as fluorescent lamp, gas discharge lighting, solid state motor drives, diodes, transistors and the increasingly common electronic power supply causes generation of harmonics [1]. Harmonics are voltages and currents which appear on the electrical system at frequencies that are integral multiples of the generated frequency. It results to a significant increase in level of harmonics and distortion in power system.

Transformers are one of the component and usually the interface between the supply and most non-linear loads. They are usually manufactured for operating at the linear load under rated frequency. Nowadays the presence of nonlinear load results in production harmonic current [2]. Increasing in harmonic currents causes extra loss in transformer winding and thus, leads to increase in temperature, reduction in insulation life, Increase to higher losses and finally reduction of the useful life of transformer [3]. Harmonic voltage increase losses in its magnetic

DOI : $10.5121 /$ acij.2011.2609 
Advanced Computing: An International Journal ( ACIJ ), Vol.2, No.6, November 2011

core while harmonic currents increased losses in its winding and structure. In general, harmonics losses occur from increased heat dissipation in the windings and skin effect both are a function of the square of the rms current, as well as from eddy currents and core losses. This extra heat can have a significant impact in reducing the operating life of the transformer insulation the increased of eddy current losses that produced by a non-sinusoidal load current can cause abnormal temperature rise and hence excessive winding losses. Therefore the influence of the current harmonics is more important. A lot of works have been done to shows that effect of harmonic effect of harmonics on loss of life of distribution transformer. Finally, a standard IEEE C57-110 entitled "recommended procedure for determination of the transformer capacity under nonsinusoidal loads". The aim in publishing this standard was providing a study of harmonic current due to various nonlinear loads are measured and a procedure for determination of the capacity of a transformer under non- Sinusoidal loads. This procedure determines the level of decreasing the rated current for risen harmonic [4]. This study looks at the transformer loss of life when the international standards on harmonics limit are referred.

\section{TRANSFORMER LOSSES IN HARMONIC LOADS}

Transformer manufacturers usually try to design transformers in a way that their minimum losses occur in rated voltage, rated frequency and sinusoidal current. However, by increasing the number of non-linear loads in recent years, the load current is no longer sinusoidal. This non-sinusoidal current causes extra loss and temperature in transformer [5]. Transformer loss is divided into two major groups, no load and load loss as shown in (1) [6, 7].

$$
\mathrm{P}_{\mathrm{T}}=\mathrm{P}_{\mathrm{NL}}+\mathrm{P}_{\mathrm{LL}}
$$

Where $\mathrm{P}_{\mathrm{NL}}$ is No load loss, $\mathrm{P}_{\mathrm{LL}}$ is Load loss, and $\mathrm{P}_{\mathrm{T}}$ is total loss. following:

A brief description of transformer losses and harmonic effects on them is presented in

2.1. No Load Loss: No load loss or core loss appears because of time variable nature of electromagnetic flux passing through the core and its arrangement is affected the amount of this loss. Since distribution transformers are always under service, considering the number of this type of transformer in network, the amount of no load loss is high but constant this type of loss is caused by hysteresis phenomenon and eddy currents into the core. These losses are proportional to frequency and maximum flux density of the core and are separated from load currents.

Many experiments have shown that core temperature increase is not a limiting parameter in determination of transformers permissible current in the non-sinusoidal currents $[4,7,8]$. Furthermore, considering that the value of voltage harmonic component is less than 5\%, only the main component of the voltage is considered to calculate no load loss, the error of ignoring the harmonic component is negligible. So, IEEE C57 .110 standards has not considered the core loss increase due to non-linear loads and has supposed this loss constant, under non-sinusoidal currents.

2.2. Load Loss: Load loss includes dc or Ohmic loss, eddy loss in windings and other stray loss and it can be obtained from short circuit test:

$$
\mathrm{P}_{\mathrm{LL}}=\mathrm{P}_{\mathrm{DC}}+\mathrm{P}_{\mathrm{EC}}+\mathrm{P}_{\mathrm{OSL}}
$$


Here,

$\mathrm{P}_{\mathrm{DC}}$ is Loss due to resistance of windings, $\mathrm{P}_{\mathrm{EC}}$ is Windings eddy current loss, $\mathrm{P}_{\mathrm{OSL}}$ is other stray losses in structural parts of transformer such as tank, clamps [7,9].

The sum of $\mathrm{P}_{\mathrm{EC}}$ and $\mathrm{P}_{\mathrm{OSL}}$ is called total stray loss. According to Eq. (3), we can calculate its value from the difference of load loss and Ohmic loss:

$$
\mathrm{P}_{\mathrm{TSL}}=\mathrm{P}_{\mathrm{EC}}+\mathrm{P}_{\mathrm{OSL}}=\mathrm{P}_{\mathrm{LL}}-\mathrm{P}_{\mathrm{DC}}
$$

It should be mentioned that there is no practical or experimental process to separate windings eddy loss and other stray loss yet [9].

\subsubsection{Ohmic Loss:}

This loss can be calculated by measuring winding dc resistance and load current. If RMS value of load current increases due to harmonic component, this loss will increase by square of RMS of load current [4]. The winding Ohmic loss under harmonic condition is shown in Eq. 4:

$$
P_{d c}=R_{d c} \times I^{2}=R_{d c} \times \sum_{h=1}^{h=h_{\max }} I_{h, \text { max }}^{2}
$$

\subsubsection{Eddy Current Loss in Windings:}

This loss is caused by time variable electromagnetic flux that covers windings. Skin effect and proximity effect are the most important phenomenon in creating these losses. In transformers, in comparison to external windings, internal windings adjacent to core have more eddy current loss. The reason is the high electromagnetic flux intensity near the core that covers these windings.

Also, the most amount of loss is in the last layer of conductors in winding, which is due to high radial flux density in this region $[4,8]$ :

$$
\mathrm{P}_{\mathrm{EC}}=\frac{\pi \tau^{2} \mu^{2}}{3 p} \mathrm{f}^{2} \times \mathrm{H}^{2} \alpha \mathrm{f}^{2} \times \mathrm{I}^{2}
$$

Here:

$\tau=$ A conductor width perpendicular to field line.

$\rho=$ Conductor's resistance.

$$
\mathrm{P}_{\mathrm{EC}} \propto \mathrm{I}^{2} \times \mathrm{f}^{2}
$$

The impact of lower-order harmonics on the skin effect is negligible in the transformer windings.

Equation shown below can be used for calculating the eddy current loss too:

$$
\mathrm{P}_{\mathrm{EC}}=\mathrm{P}_{\mathrm{LL}-\mathrm{R}}-\left[\left(\mathrm{R}_{1} \mathrm{I}_{1-\mathrm{R}}^{2}-\mathrm{R}_{2} \mathrm{I}_{2-\mathrm{R}}^{2}\right)\right]
$$

According to IEEE C57 .110 standards, the amount of rated eddy current loss of windings is about $33 \%$ of total stray loss for oil-filled transformers:

$$
\mathrm{P}_{\mathrm{EC}-\mathrm{R}}=0.33 \mathrm{P}_{\mathrm{TSL}}
$$


2.3. Other Stray Loss: Due to the linkage between electromagnetic flux and conductor, a voltage induces in the conductor and this will lead to producing eddy current Eddy current produces loss and increases temperature. A part of eddy current loss which is produced in structural parts of transformers (except in the windings) is called other stray loss [7, 10]. Many factors such as size of core, class of voltage of transformer and construction of materials used to build tank and clamps [11]. To determine the effect of frequency on the value of other stray loss, different tests have been fulfilled. Results shown that the ac resistance of other stray loss in low frequency $(0-360 \mathrm{~Hz})$ is equal to:

$$
R_{A C}^{i f}=0.00129\left(\frac{f_{h}}{f_{1}}\right)^{0.8}
$$

The frequencies in the range of $(420-1200 \mathrm{~Hz})$, resistance will be calculated by:

$$
R_{A C}^{h f}=0.33358\left(\frac{f_{h}}{f_{1}}\right)^{-1.87}
$$

Thus this loss is proportional to the square of the load current and the frequency to the power of 0.8

$$
\mathrm{P}_{\mathrm{EC}} \propto \mathrm{I}^{2} \propto \mathrm{f}^{0.8}
$$

Below equation can be used for calculating the other stray loss

$$
\mathrm{P}_{\mathrm{OSL}}=\mathrm{P}_{\mathrm{TSL}}-\mathrm{P}_{\mathrm{EC}}
$$

\section{EFFECT OF HARMONICS ON NO-LOAD LOSSES}

According to Faraday's law the terminal voltage determines the transformer flux level, i.e.:

$$
\mathrm{N} \frac{d \Phi}{d t}=\mathrm{v}(\mathrm{t})
$$

Transferring this equation into the frequency domain shows the relation between the voltage harmonics and the flux components:

$$
\mathrm{Nj}(\mathrm{h} \omega)=\mathrm{V}_{\mathrm{h}}
$$

This equation shows that flux magnitude is directly proportional to the harmonic voltage and inversely proportional to the harmonic order h. Furthermore, within most power systems, the harmonic distortion of the system voltage THD is well below 5\% and the magnitudes of the voltage harmonic components are small compared to fundamental component. Hence neglecting the effect of harmonic voltage will only give rise to an insignificant error. This is confirmed by measurements in [12]. Nevertheless, if THDv is not negligible, losses under distorted voltages can be calculated based on ANSI-C.27-1920 standard with (14).

$$
P=P_{M}\left[P_{h}+P_{e c}\left(\frac{V_{h r m s}}{V_{r m s}}\right)^{2}\right]
$$

Where,

$\mathrm{V}_{\text {hrms }}$ and $\mathrm{V}_{\text {rms }}$ are the RMS values of distorted and sinusoidal voltages, $\mathrm{P}_{\mathrm{M}}$ and $\mathrm{P}$ are no-load losses under distorted and sinusoidal voltages, $\mathrm{P}_{\mathrm{h}}$ and $\mathrm{P}_{\mathrm{EC}}$ are hysteresis and eddy current losses, respectively [13]. 


\section{EFFECT OF HARMONICS ON LOAD LOSSES:}

As per [4], in most power systems, current harmonics are of more significance. It causes increase losses in the windings and other structural parts of the distribution transformer.

\subsection{Effect of Harmonics on DC Losses:}

If the rms value of the load current is increased due to harmonic components, then these losses will increase by square of RMS of load current. The windings Ohmic loss under harmonic condition is shown by:

$$
P_{d c}=R_{d c} \times I^{2}=R_{d c} \times \sum_{h=1}^{h=h_{\max }} I_{h, \text { max }}^{2}
$$

\subsection{Effect of Harmonics on Eddy Current Losses:}

As mentioned above, eddy current loss of windings is proportional to square of current and square of harmonic frequency in harmonic condition. In following equation, this loss is calculated:

$$
P_{E C}=P_{E C-R} \times \sum_{h=1}^{h=h_{\max }} h^{2}\left[\frac{I_{h}}{I_{R}}\right]^{2}
$$

Where, $\mathrm{P}_{\mathrm{EC}-\mathrm{R}}$ is Rated eddy current loss of windings, $\mathrm{I}_{\mathrm{h}}$ is the current related $\mathrm{h}^{\text {th }}$ harmonics $\mathrm{I}_{\mathrm{R}}$ is Rated load current, $\mathrm{h}$ is the Order of harmonics. Also, the harmonic loss factor for eddy current

loss of winding can be defined according to [4]:

$$
F_{H L}=\frac{\sum_{h=1}^{h=h_{\max }} h^{2} I_{h}{ }^{2}}{\sum_{h=1}^{h=h_{\text {max }}} I_{h}{ }^{2}}=\frac{\sum_{h=1}^{h=h_{\max }} h^{2}\left[\frac{I_{h}}{I_{R}}\right]^{2}}{\sum_{h=1}^{h=h_{\max }}\left[\frac{I_{h}}{I_{R}}\right]^{2}}
$$

\subsection{Effects of Harmonics on Other Stray Losses:}

The other stray losses are assumed to vary with the square of the rms current and the harmonic frequency to the power of 0.8 :

$$
P_{\text {OSL }}=P_{\text {OSL }-R} X \sum_{h=1}^{h=h_{\max }} h^{0.8}\left[\frac{I_{h}}{I_{R}}\right]^{2}
$$

Harmonic loss factor for other stray losses is expressed in a similar form as for the winding eddy currents.

$$
F_{H L-S T R}=\frac{P_{O S L}}{P_{O S L-R}}=\frac{\sum_{h=1}^{h=h(\max )} h^{0.8}\left[\frac{I_{h}}{I_{R}}{ }^{2}\right.}{\sum_{h=1}^{h=h(\max )}\left[\frac{I_{h}{ }^{2}}{I_{R}}{ }^{2}\right.}
$$


Advanced Computing: An International Journal ( ACIJ ), Vol.2, No.6, November 2011

So under non-sinusoidal currents it is only necessary to multiply the rated other stray loss by harmonic loss factor, $\mathrm{F}_{\mathrm{HL}-\mathrm{STR}}$.

\section{EVALUATION OF LOSSES AND CAPACITY OF TRNSFORMER IN HARMONIC LOADS:}

When a transformer is utilized under non-sinusoidal voltages and currents, due to loss increase results, increase of temperature, and its rated power must decrease. This action will be possible by limiting total transformer loss under non-sinusoidal current to the amount of loss in sinusoidal voltage and load current. In other word, maximum permissible current of transformer in harmonic load must be determined as its loss would be equal to the loss in hot spot and under sinusoidal current condition. The equation that applies to linear load conditions is [14]

$$
P_{L L-R}(p u)=1+P_{E C-R}(P u)+P_{O S L-R}(P u)
$$

Where, $\mathrm{P}_{\mathrm{LL}-\mathrm{R}}$ is Rated load losses, 1 is per unit amount of dc losses , $\mathrm{P}_{\mathrm{EC}-\mathrm{R}}$ is Eddy current loss, $\mathrm{P}_{\mathrm{OSL}-\mathrm{R}}$ is Other Stray loss in rated current.

As the effect of harmonic on losses of transformer evaluated in previous sections, a general equation for calculating of losses when transformer supplying a harmonic load can be defined as follows:

$P_{L L-R}(P u)=I^{2}(p u) \times\left[1+F_{H L} \cdot P_{E C-R}(p u)+F_{H L-S T R .} P_{O S L-R}(p u)\right]$

So, maximum permissible load current to determine the capacity reduction of transformer is expressed as [4]:

$\mathrm{I}_{\max }(p u)=\sqrt{\frac{P_{L L-R}(p u)}{1+\left[F_{H L} \cdot P_{E C-R}(p u)\right]+\left[F_{H L-S T R} P_{O S L-R}(p u)\right]}}$

From above equation, we can determine the maximum permissible load current of transformer and also we can evaluate its capacity reduction under the effects of non-sinusoidal current of transformer.

\section{CALCULATION OF LOSSES AND CAPACITY OF TRANSFORMER UNDER HARMONIC LOADS}

In this section calculation and simulation of losses and capacity of transformer under harmonic loads is performed. the distortion in the voltage and current waveforms deteriorates the performance of the equipment connected in distribution systems. The analysis of harmonics is essential to determine the performance and designing of these equipments. The voltage and current waveforms of some of the commonly used loads and their harmonics have been recorded by using power analyzer (HIOKI 3193). The total harmonic distortion is used as a harmonic index to identify the effects of different nonlinear loads. Some of the most commonly used domestic loads are examined under harmonics conditions with power analyzer are as follows: 
Advanced Computing: An International Journal ( ACIJ ), Vol.2, No.6, November 2011

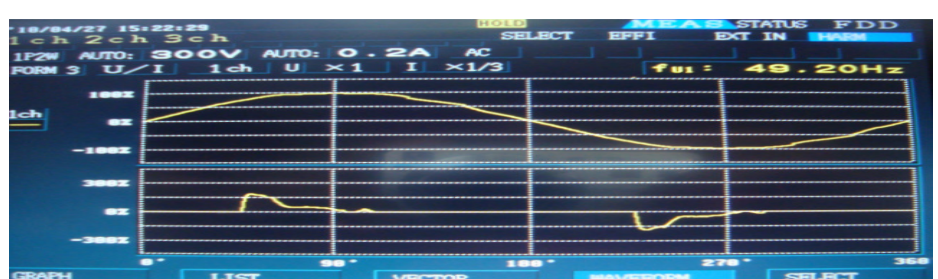

Figure 1: waveform for C.F.L.

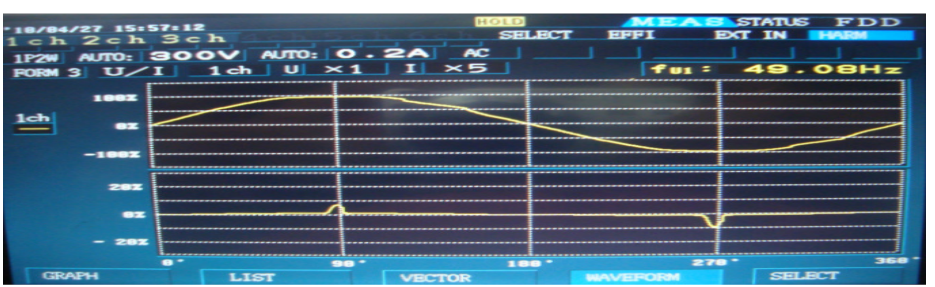

Figure 2: waveform for Laptop

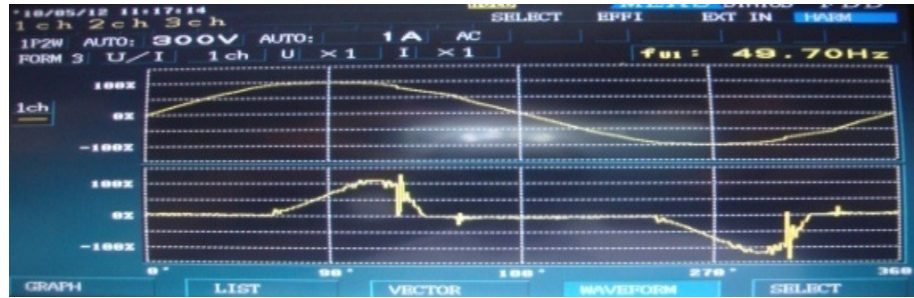

Figure 3: waveform for Computer

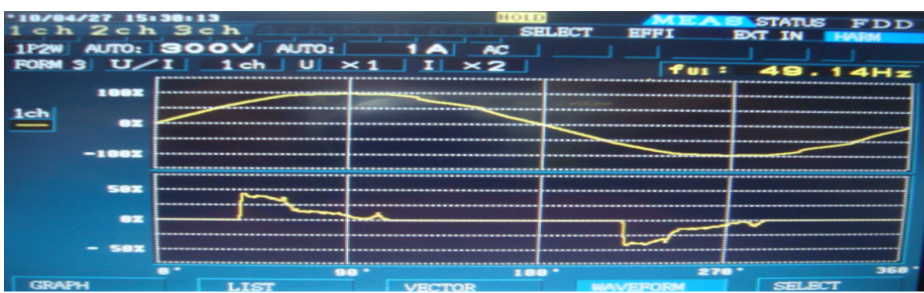

Figure 4: waveform for E.T.L.

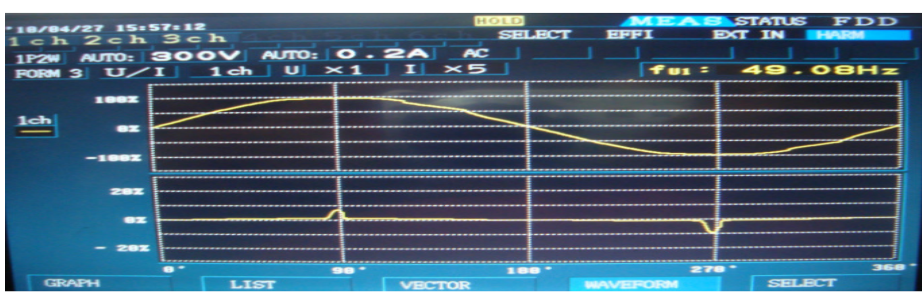

Figure 5: waveform for Mobile Charger

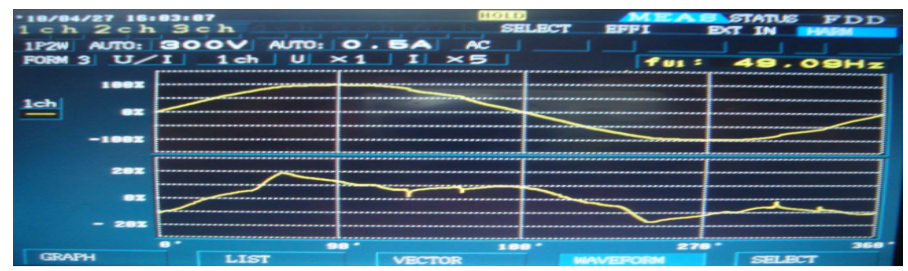

Figure 6: waveform for U.P.S. 
The distortion in waveforms deteriorates the performance of equipment connected in distribution system. The analysis of the harmonics is essential to determine the performance and designing of equipments. The total current distortion (THD) varies from $200 \%$ for some loads to a few percentages for other loads. It can result to malfunction of electrical system components. The observations are shown below in Table 1:

TABLE 1: ANALYSIS OF SOME COMMONLY USED RESIDENTIAL EQUIPMENT

\begin{tabular}{|c|c|c|c|c|c|c|c|c|}
\hline Non-linear loads & $\mathrm{V}_{\text {rms }}$ & $\mathrm{I}_{\text {rms }}$ & \multicolumn{1}{l}{ KVA } & \multicolumn{2}{l}{ DPF } & \multicolumn{1}{l}{ TPF } & $\begin{array}{l}\text { Extra Units } \\
\text { rms }\end{array}$ & \multicolumn{2}{|c|}{$\begin{array}{l}\text { Extra KVA } \\
\text { Consumed }\end{array}$} & $\begin{array}{c}\text { Harmonics } \\
\%\end{array}$ \\
\hline Incandescent Bulb & 213.95 & 0.4129 & 0.09087 & 0.99 & 1 & 0.0105 & 0.0105 & $2.85 \%$ \\
\hline CFL & 214.81 & 0.1094 & 0.02247 & 0.91 & 0.63 & 0.021 & 1.3065 & $126.48 \%$ \\
\hline Computer & 212.88 & 1.1305 & 0.24066 & 0.95 & 0.81 & 0.075 & 3.945 & $138.68 \%$ \\
\hline ETL & 212.51 & 0.1627 & 0.03587 & 0.86 & 0.64 & 0.0345 & 1.4205 & $91.06 \%$ \\
\hline Mobile charger & 215.92 & 0.0311 & 0.00761 & 0.98 & 0.54 & 0.0369 & 0.582 & $144.73 \%$ \\
\hline UPS & 213.94 & 0.1132 & 0.02421 & 0.93 & 0.85 & 0.0211 & 0.4665 & $51.68 \%$ \\
\hline Laptop & 216.82 & 0.2606 & 0.0567 & 0.97 & 0.42 & 0.059 & 4.77 & $204.3 \%$ \\
\hline Television & 216.71 & 0.3289 & 0.0833 & 0.99 & 0.61 & 0.141 & 4.321 & $124.73 \%$ \\
\hline
\end{tabular}

In Table 1 some of the commonly used residential loads are explained in terms of harmonic parameters [15] as follows:

Root Mean Square (RMS) Value: Since rms values gives the precise value comparative to average value in the presence of harmonics.

Total harmonic distortion (THD): It represents the sum of the total harmonics that are impacting an electrical system, which causes distortion in voltage or current waveforms. This value is expressed as a percentage.

Displacement Power Factor (DPF):.Displacement power factor (DPF) is present in the sinusoidal quantities like current and voltage in case of linear loads.

Total Power Factor (TPF): In power system causes the apparent power to exceed the active power by a substantial amount. Under these situations, the form of power factor present is called distortion power factor. It results the sum of the displacement and distortion power factors is the total power factor (TPF).

The abundance of non-linear loads now is being placed on electrical system, the displacement power factor (DPF) as being the total power factor (TPF). The harmonic current results TPF to be low, while the DPF could be relatively high.

Transformer manufacturers usually try to design the transformers in a way that their minimum losses occur in rated voltage, rated frequency and sinusoidal current. However by increasing the number of non-linear loads in recent years, the load current is no longer sinusoidal. This nonsinusoidal current causes extra losses and temperature in transformer. There are two methods 
explained for calculation of losses and capacity of distribution transformer under harmonics loads as follows:

\subsection{Analytical Method:}

The generic parameters of a $100 \mathrm{KVA}$ three phase distribution transformer that designed with specifications are summarized in Table 2.The total stray loss $\mathrm{P}_{\mathrm{TSL}}$ can be calculated as follows:

$\mathrm{P}_{\mathrm{TSL}}=\mathrm{P}_{\mathrm{L}}-\mathrm{P}_{\mathrm{DC}}=1760-3\left[\mathrm{I}_{1}^{2} \mathrm{R}_{1}-\mathrm{I}_{2}^{2} \mathrm{R}_{2}\right]=110 \mathrm{~W}$

The winding eddy current loss and other stray loss are

$\mathrm{P}_{\mathrm{EC}}=0.33[110]=36.3 \mathrm{~W}$

$\mathrm{P}_{\mathrm{OSL}}=110-36.3=73.7 \mathrm{~W}$

TABLE 2.TRANSFORMER PARAMETER

\begin{tabular}{|l|l|l|l|l|l|}
\hline $\mathrm{V}_{1}(\mathrm{~V})$ & $\mathrm{V}_{2}(\mathrm{~V})$ & $\mathrm{I}_{1}(\mathrm{~A})$ & $\mathrm{I}_{2}(\mathrm{~A})$ & $\mathrm{P}_{\mathrm{O}}(\mathrm{W})$ & $\mathrm{P}_{\mathrm{SC}}(\mathrm{W})$ \\
\hline 11000 & 433 & 5.25 & 133.3 & 260 & 1760 \\
\hline
\end{tabular}

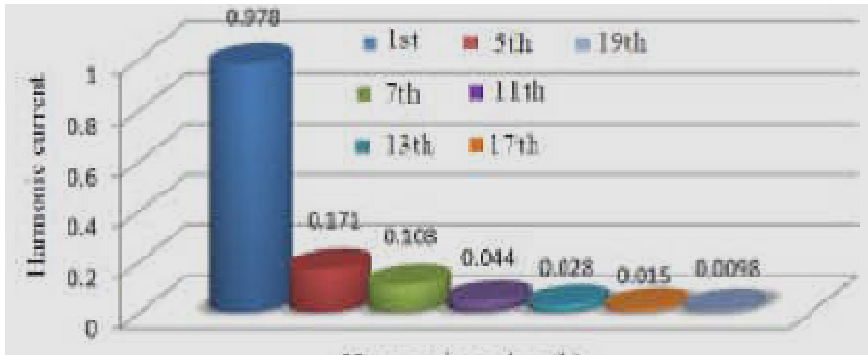

Harmetuic order (h)

Figure 7:Non-linear Load Specification for Studied Transformer

If transformer supplying a load with specification in Table 3 losses on harmonic load calculated as follows:

\section{TABLE 3: HARMONIC LOAD SPECIFICATION[1]}

\begin{tabular}{|l|l|l|l|l|l|l|}
\hline 1 & 5 & 7 & 11 & 13 & 17 & 19 \\
\hline 0.978 & 0.171 & 0.108 & 0.044 & 0.028 & 0.015 & 0.009 \\
\hline
\end{tabular}

The harmonic loss factor for eddy current winding and other stray losses are:

$\mathrm{F}_{\mathrm{HL}}=3.734$ and $\mathrm{F}_{\mathrm{HL}-\mathrm{STR}}=1.202$.

Table 4 shows losses under harmonic load. Total loses increases about $23.1 \%$ under harmonic condition load. These increase in total losses results from significant increase in eddy current losses in winding. 
TABLE 4: LOSSES UNDER HARMONIC LOAD

\begin{tabular}{|c|c|c|c|c|}
\hline $\begin{array}{l}\text { Types of } \\
\text { losses }\end{array}$ & $\begin{array}{l}\text { Rated } \\
\text { losses } \\
(\mathrm{W})\end{array}$ & $\begin{array}{l}\text { Losses } \\
\text { under } \\
\text { harmonic } \\
\text { load } \\
\text { current } \\
(\mathrm{W})\end{array}$ & $\begin{array}{l}\text { Harmonic } \\
\text { losses } \\
\text { factor }\end{array}$ & $\begin{array}{l}\text { Corrected } \\
\text { losses } \\
\text { under } \\
\text { harmonic } \\
\text { load (W) }\end{array}$ \\
\hline No-load & 260 & 260 & ------ & 260 \\
\hline Dc & 1650 & 1985.23 & ------ & 1985.23 \\
\hline $\begin{array}{c}\text { Winding } \\
\text { eddy } \\
\text { current }\end{array}$ & 36.3 & 38.805 & 3.734 & 144.92 \\
\hline $\begin{array}{c}\text { Other } \\
\text { stray }\end{array}$ & 73.3 & 78.79 & 1.202 & 94.67 \\
\hline Total & 2020 & 2141.45 & ------ & 2486.6 \\
\hline
\end{tabular}

In addition from (23), the rms value of the maximum permissible non-sinusoidal load current with the given harmonic component is:

$\mathrm{I}_{\max }(\mathrm{pu})=\sqrt{\frac{\mathbf{1 . 1 1 9}}{\mathbf{1 . 6 1 2}}}=0.8337$

\section{$0.8337 \times 133.3=111.13 \mathrm{Amp}$}

Equivalent $\mathrm{KVA}=100 \times 0.8337=83.37 \mathrm{KVA}$

\subsection{Simulation method}

MATLAB/simulink is used to simulate the obtained transformer model for the $100 \mathrm{KVA}$ three phase distribution transformers and to evaluate the capacity and losses under harmonic loads condition. Basically Transformers model consist of ordinary parameters such as the leakage inductances and dc resistances, magnetizing inductances and core resistance that can be obtained from noload test, short circuit test and dc test. In this model, stray losses that consist of eddy current losses in windings and other stray losses do not considered. When transformer supplies harmonic loads the losses that are proportional with frequency is more considerable. Figure 8 shows the proposed transformer model with the proximity effect loss represented as a potential difference defined as the second derivative of the load current and the other stray losses represented as a resistor in series with the leakage inductance and dc resistance [16].

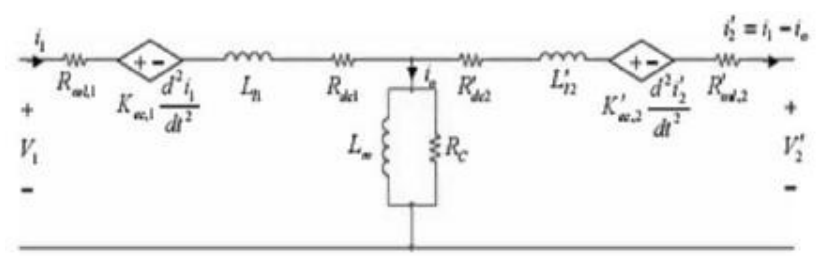

Figure 8: Proposed Equivalent Transformer Model Referred to Primary Side 
The parameters required to simulate the transformer are summarized in Table 5.

TABLE 5: LOSSES UNDER HARMONIC LOAD BY SIMULATION

\begin{tabular}{|c|c|c|}
\hline $\begin{array}{c}\text { Types of } \\
\text { losses }\end{array}$ & $\begin{array}{c}\text { Rated losses } \\
(\mathrm{w})\end{array}$ & $\begin{array}{c}\mathrm{P}_{\mathrm{LL}} \text { losses under } \\
\text { rms harmonic } \\
\text { load current(w) }\end{array}$ \\
\hline No-load & 262.54 & 262.54 \\
\hline $\mathrm{dc}$ & 1647.76 & 1983.22 \\
\hline $\begin{array}{c}\text { Winding } \\
\text { eddy current }\end{array}$ & 31.94 & 132.58 \\
\hline Other stray & 74.24 & 92.81 \\
\hline Total & 2016.48 & 2471.15 \\
\hline
\end{tabular}

MATLAB/Simulink is used to simulate the obtained transformer model. Figure 9 shows the in proposed model of transformer MATLAB/Simulink supplied to a colony having 11 houses .Current sources with different frequencies are put in parallel to model for harmonics in residential loads. The power losses are determined through simulations $\&$ summarized on Table 5.Thus, the rms value of the maximum permissible non-sinusoidal load current composition from equation (23) is with given harmonics [16]:

$\mathrm{I}_{\max }(\mathrm{pu})=\sqrt{\frac{\mathbf{1 . 1 2 1}}{\mathbf{1 . 5 7 3}}}=0.8441$

$\mathrm{I}_{\max }=0.8441 \times 133.3=112.52 \mathrm{Amp}$

Equivalent $\mathrm{KVA}=100 \times 0.8443=84.43 \mathrm{KVA}$

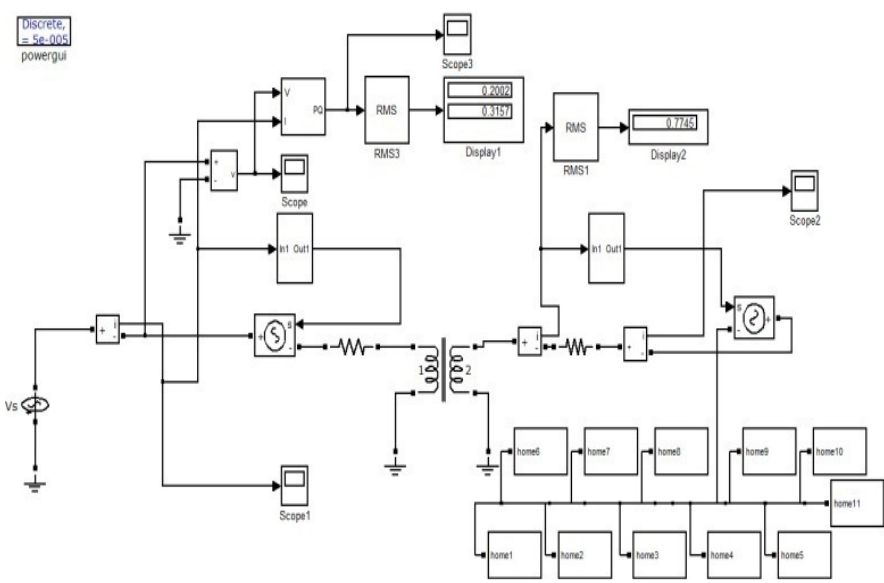

Figure 9: Simulation Model for Transformer

The comparison between two steps (Table 6) shows that the predicted values using analytical and simulation methods are similar but simulations shows smaller losses then the analytical method. The reason is that in the analytical method it is assumed that the eddy current 
Advanced Computing: An International Journal ( ACIJ ), Vol.2, No.6, November 2011

losses are proportional with the square of harmonic orders that is a permissible assumption. In [17] a corrected winding eddy current loss factor is presented which confirm this.

TABLE 6: COMPARISON BETWEEN ANALYTICAL AND SIMULATION METHOD

\begin{tabular}{|c|c|c|}
\hline Conclusion & $\begin{array}{c}\text { Based on } \\
\text { analytical } \\
\text { method }\end{array}$ & $\begin{array}{c}\text { Based on } \\
\text { simulation } \\
\text { method }\end{array}$ \\
\hline $\begin{array}{c}\text { Losses under linear } \\
\text { load(w) }\end{array}$ & 2020 & 2016.48 \\
\hline $\begin{array}{c}\text { Losses under harmonic } \\
\text { load (w) }\end{array}$ & 2484.6 & 2471.15 \\
\hline $\begin{array}{c}\text { Percent of increase } \\
\text { losses }\end{array}$ & $23.01 \%$ & $22.54 \%$ \\
\hline $\begin{array}{c}\text { Capacity under } \\
\text { harmonic load (KVA) }\end{array}$ & 83.37 & 84.43 \\
\hline $\begin{array}{c}\text { Percent of decrease } \\
\text { capacity }\end{array}$ & $16.63 \%$ & $15.57 \%$ \\
\hline
\end{tabular}

\section{CONCLUSION}

The wide spread utilization of electronic devices has significantly increased the numbers of harmonic generating apparatus in the power systems. This harmonics cause distortions of voltage and current waveforms that have adverse effects on electrical equipments. These harmonics effect on power system can be summarized as increased losses of devices, equipment heating \& loss of life.

In this paper, impacts of harmonic components on transformers have been reviewed and analyzed. Effects of non-linear loads on transformer losses based on the conventional method (IEEE standard C57-110) have been studied for derating purpose. The harmonic losses factor for eddy current winding and other stray losses has been computed in order to evaluate the equivalent KVA of the transformer for supplying non-linear loads. It increased transformer loss caused by non-linear loads leads to an increase in transformer temperature, fatigue and premature failure of insulator and transformer life reduction. Therefore under harmonic load currents, to prevent the described problems, the capacity of transformer must be supposed smaller. Then, a MATLAB/simulink model is adapted to estimate the losses in distribution transformer and capacity under harmonic load condition. This method has been used as a very precise method for calculating the loss of the transformer under linear and non-linear load currents. Then finally the losses and capacity of transformer were evaluated with analytical and simulation methods. The comparison shows that predicted values using analytical and simulation methods are similar but simulation method shows smaller losses than the analytical method. So for power system with transformer, it is better to carry out monitoring on voltage and current, to reach to useful capacity of transformer based on available standards and the proposed model, if harmonic components exist. 


\section{REFERENCES}

[1] Pierce, L.W., 1996. Transformer design and application considerations for nonsinusoidal load currents. IEEE Transaction on Industry Applications, 32(3): 633-645.

[2] Makarov, S.N. and A.E. Emanuel, 2000. Corrected Harmonic Loss Factor For Transformers supplying Non-sinusoidal Load current. In the Proceedings of IEEE 9th International conference on Harmonics and Power Quality, vol. 1, Oct.2000, pp.87-90.

[3] Faiz, J., M.B.B. Sharifian and A. Fakhri, 2007. Two-dimensional finite element thermal modeling of oil-immersed transformer. European Transaction on Electrical Power, 18: 577-594.

[4] IEEE Standard C57.110-1998, IEEE Recommended Practice for Establishing Transformer Capability when Supplying Non-sinusoidal Load Currents. IEEE Standards.

[5] Sadati, S.B., A. Tahani, B. Darvishi, M. Dargahi and H. Yousefi, 2008. Comparison of Distribution Transformer Losses and Capacity under Linear and Harmonic Loads. In the proceedings of the IEEE $2^{\text {nd }}$ International Power and Energy Conference, 2008, PP: 1265-1269.

[6] Sharifian, M.B.B., Faiz, J., Fakheri, S.A. and Zraatparvar, A. (2003). Derating of Distribution Transformers for Non-Sinusoidal Load Currents Using Finite Element Method. ICECS 2003. Proceedings of the 2003, $10^{\text {th }}$ IEEE International Conference on Electronics, Circuits and Systems. 14-17 December. Iran: IEEE, 754-757.

[7] Jayasinghe, N.R., Lucas, J.R. and Perera, K.B.I.M., 2003. Power System Harmonic Effects on Distribution Transformer and New Design considerations for K Factor transformers. IEEE Sri Lanka Annual Sessions. September 2003. Sri Lanka: IEEE.

[8] Fuchs, E.F., D. Yildrim and W. Mack Grady, 2000. Measurement of eddy current loss coefficient pec-r, derating of single-phase transformers and comparison with k-factor approach. IEEE transaction on Power Delivery, 15(1):148-154.

[9] Linden W. Pierce, Transformer Design and Application Considerations for Nonsinusoidal Load Currents. IEEE Transaction on Industry Application Vol. 32, No.2, PP 633645 May/June 1996.

[10] Olivares, J.C., E. Perez, S.V. Kulkarni, F. De Leond and M.A. Venagas-Vega, 2004. 2D finite-element determination of tank wall losses in pad-mounted transformers, ELSEVIER Electric Power System Res. 71:179-185.

[11] Radmehr, M.; Farhangi, S.; Nasiri, A. (2006). Effect of Power Quality Distortion on Electrical Drives and Transformer Life in Paper Industries: Simulation and Real Time 
Advanced Computing: An International Journal ( ACIJ ), Vol.2, No.6, November 2011

Measurements. Pulp and Paper Industry Technical Conference, 2006. 18-23 June 2006. Iran: IEEE, 1-9.

[12] A Girgis, E. Makram, J. Nims, Evaluation of temperature rise of distribution transformer in the presence of harmonic distortion. Electric Power Systems Research, vol. 20, no.1, Jan 1990, pp.15-22.

[13] D.S. Takach, Distribution Transformer No Load Losses, IEEE Trans. on PAS, Vol. 104, No. 1, 1985, pp. 181-193.

[14] A.H. Al-badi, A. Elmoudi, I. Metwally. Losses reduction in distribution transformers, Proceedings of the International Multi Conference of Engineers and Computer Scientists 2011, Vol. II, IMECS 2011, March 16-18, 2011, Hong Kong.

[15] Palko, Ed. Living with power system harmonics. Plant Engineering, 46.11 (1992). Info.Trac Engineering Collection.

[16] S.B.Sadati, A.Tahani, M.Jafari, M.Dargahi, Derating of transformers under Nonsinusoidal Loads, Proc. of the $11^{\text {th }}$ International Conference on Optimization of Electrical and Electronic Equipment OPTIM 2008, Brasov, Romania.

[17] S. N. Makarov, A. E. Emanuel, Corrected Harmonic Loss Factor For Transformers supplying Non-sinusoidal Load current Proc. of the 9th International conference on Harmonics and Power Quality, vol. 1, Oct.2000, pp.87-90. 